\title{
The Relationship Between Empathic Tendency, Life Satisfaction and Professional Self-esteem Among Turkish Military Health Students
}

Yasin uzuntarla ( $\square$ yasinuzuntarla@gmail.com )

Gülhane Askerî Tıp Akademisi https://orcid.org/0000-0002-5021-3763

Fatih Orhan

Saglik Bilimleri Universitesi

\section{Research}

Keywords: Empathic Tendency, Life Satisfaction, Professional Self-Esteem, Military Health Students

Posted Date: June 8th, 2020

DOI: https://doi.org/10.21203/rs.3.rs-32679/v1

License: (c) (i) This work is licensed under a Creative Commons Attribution 4.0 International License.

Read Full License 


\section{Abstract}

Background: This study aims to reveal the relationship among empathic tendencies, life satisfaction and professional self-esteem of the Turkish military students of the school of medicine, nursing and health vocational school. Besides, the study sought to determine whether there was a mediating role of professional self-esteem between the empathetic tendency and life satisfaction of the students receiving health education.

Methods: The study is arranged in accordance with the relational screening model. 870 Turkish military health students participated in the study with a survey participation rate of $95.3 \%$. To analyze the hypothesized path model, data were analyzed using SPSS 23 and AMOS 24 programs.

Results: $61.3 \%$ of participants were male and $38.7 \%$ were female. Of the 870 participants, 439 were medicals, 323 were nurses and 108 were vocational school students studying at a military medical academy. Model data fit index values were found to be within acceptable limits.

Conclusions: The empathic tendency, life satisfaction and professional self-esteem levels in students receiving health education are high. There is a positive and significant relationship between the variables examined. It was found that professional self-esteem has a partial mediating role in the relationship between empathic tendency and life satisfaction.

\section{Background}

Health personnel's attitudes and behaviors play an important role in providing health services effectively and efficiently, as well as the quality of the service, the suitability of the price, the speed, the ease of access, the simple examination/treatment processes, and the comfortable and clean physical environment. Friendly, open-minded and understanding healthcare workers who do their jobs with love and respect raise the quality of health services and patient satisfaction to the highest levels. At this point, we come across the fact that the healthcare personnel should have sufficient knowledge as well as some different social characteristics. When the literature is reviewed, the most prominent of these concepts are empathic tendency, life satisfaction and professional self-esteem [1].

Empathy is a widely used but little understood concept. The word meaning of empathy is understanding of the emotional state of another person or to have concern or sympathy for others. Empathy includes other people's thoughts, feelings, desires, beliefs, status, point of view or experiences and the tendency to experience others' internal situations as ours [2,3]. In summary, empathy is expressed as an empathic tendency. Thanks to the empathic tendency, individuals can establish well-balanced dialogues [4]. An empathic tendency is the emotional aspect of empathy and shows the potential of the individual to empathize. The empathetic tendency is an innate personal trait. It is very difficult to change in personality and attitude as it requires a change as opposed to a skill or a cognitive trait [5]. 
Life satisfaction reflects an individual's assessment of life as a whole. Individuals who are satisfied with life can better cope with problems, show better work performance, become more resistant to stress, and moreover their physical health seems to be better [6]. In other words, life satisfaction is a cognitive evaluation based on the individual's ability to judge his or her own life according to various criteria. It contains the whole life of the person and various dimensions of this life; It is also affected by many factors such as age, gender, health, work-life, economic situation, education level, religion, marriage, social support and environmental conditions [7].

Self-esteem is fundamental to a person's life experience. Self-esteem is a prerequisite for individual harmony and mental health, while professional self-esteem is a prerequisite for professional harmony and satisfaction [8]. Professional self-esteem can also be defined as the credit given to the chosen profession. Professional self-esteem reveals how valuable and important one sees his/her profession and is seen as a prerequisite for professional harmony and satisfaction [9]. Professional self-esteem allows professionals to understand [10].

This study aims to reveal the relationship among empathic tendencies, life satisfaction and professional self-esteem of the Turkish military students of the school of medicine, nursing and health vocational school. Besides, the study sought to determine whether there was a mediating role of professional selfesteem between the empathetic tendency and life satisfaction of the students receiving health education.

\section{Materials And Methods}

This study was carried out with military health students studying in the Turkish Armed Forces, Gülhane Military Medical Academy (GMMA) in Ankara/Turkey. Students graduate as a medical officer at the end of 6 years of education in medical faculty, military nurse at the end of 4 years of education in nursing faculty, paramedic, laboratory, dental technician vs. (non-commissioned officers of health) at the end of 2 years of education in health vocational school. Within the scope of the study, all students $(n=913)$ were tried to be reached by face-to-face interview technique. 439 (91.8\%) of 478 students in medical faculty, $323(98.7 \%)$ of 327 students in the nursing faculty, and 108 (100\%) of vocational high school participated in the study and the overall survey participation rate was $95.3 \% .61 .3 \%$ of participants were male and $38.7 \%$ were female. The research was carried out in accordance with the Declaration of Helsinki Ethical Rules with 870 students who voluntarily participated between April and June 2016.

\subsection{Questionnaire}

In the study, the survey method was used as a data collection tool. The questionnaire consists of three parts.

\subsubsection{Empathic Tendency Scales (ETS)}

ETS developed by Dokmen was used to measure the empathic tendency levels of the participants. The scale is a five-point Likert type and consists of 20 items and one dimension. The items of the scale were 
scored as " 5 " if it was completely appropriate and " 1 " if it was completely inconsistent. 12 of the 20 articles contain positive and 8 contain negative statements. The scores that can be taken on the scale vary between 20-100 and the high score indicates that the level of empathic tendency is also high. It was applied by Dokmen to a group of 70 students twice, three weeks apart, with the method of repeating the scale. The reliability of the resulting scale is 0.82 . Split-half reliability of the scale between the scores of the sample from the single or double items of the scale was found 0.86 . The scale's reliability coefficient calculated with Cronbach Alpha (CA) for the research group was found to be 0.72 [11].

\subsubsection{Life Satisfaction Scale (LSS)}

LSS, developed by Diener et al. and adapted to Turkish by Koker, was used to measure participants' life satisfaction levels $[12,13]$. The scale consists of 5 items in seven Likert type and one dimension. If the items of the scale are completely appropriate, they are scored as "7" points and if it is completely contrary, they are scored as "1" points. The scores that can be obtained from the scale vary between 5 and 35 , and high scores indicate that the individual has positive perceptions about his/her life. In the original study, the CA internal consistency coefficient of the scale was 0.87 ; in the study conducted by Koker, the CA internal consistency coefficient of the scale was found to be 0.76 [13].

\subsubsection{Professional Self-Esteem Scale (PSES)}

PSES developed by Arıcak was used to measure the level of professional self-esteem of the participants. The scale consists of 30 items in five Likert type and one dimension. If the items of the scale are completely appropriate, they are scored as " 5 " points and if it is completely contrary, they are scored as "1" points. 14 of the 30 articles contain positive and 16 contain negative statements. The scores that can be obtained from the scale vary between 30-150 and the high score indicates that the level of professional self-esteem is high. In the original study, the CA reliability coefficient of the scale was found to be 0.93 [14].

\section{Limitations}

The limitation of this research is that the study covers only faculty of medicine, nursing and vocational school students studying at GMMA.

\subsection{Statistical Analysis}

In this study, in which quantitative research was carried out, data was collected using the survey method. Firstly, data entry was done using SPSS 23 statistical program. After the control of the data set and the preparation for the analysis (preliminary analysis) were completed, the demographic characteristics of the participants were determined. Later, the structure validity of the research model was tested with Confirmatory Factor Analysis (CFA) using the AMOS 24 program. Then the average and standard deviation values of the variables in the research model were calculated using SPSS 23 statistical program and reliability and Pearson correlation analyzes were performed. The research hypothesis was 
tested using Structural Equation Modeling (SEM) using the AMOS 24 program. The statistical value of $p$ $<0.05$ was considered significant.

\subsection{Model and Hypotheses of the Research}

The hypotheses established within the framework of the main purpose of the research are as follows:

Hypothesis $1(\mathrm{H} 1)$ : Empathetic tendency positively affects life satisfaction,

Hypothesis 2 (H2): Empathetic tendency positively affects professional self-esteem,

Hypothesis 3 (H3): Professional self-esteem affects life satisfaction positively,

Hypothesis $4(\mathrm{H} 4)$ : Professional self-esteem mediates the relationship between empathic tendency and life satisfaction.

The structural model constructed in the research is given in Figure 1:

In order to test the research model and hypotheses in this study, the causality approach and contemporary approach of Baron and Kenny [15] were used together in the Structural Equation Model mediation analysis. According to Baron and Kenny [15];

1. The predictor variable should significantly affect the predicted variable.

2. The predictor variable should significantly affect the mediator variable.

3. When the predictor and the mediator variable are included in the analysis together, the mediator variable should significantly affect the predicted variable.

4. When the effect of both the predictor and the mediator variable on the predicted variable is tested, a "partial" mediation effect occurs if the predictor variable's effect on the predicted variable decreases. If this effect becomes meaningless, a "full" mediation effect occurs.

In recent years, serious criticism has been made about the causality approach and a contemporary approach has been put forward for its use in mediating models [16]. In the contemporary approach, the main point in the mediation model analysis is to evaluate indirect effects. According to this approach, indirect impact values should not contain 0 (zero) value in $95 \%$ confidence interval according to bootstrap test results. In the Bootstrap method, new observation sets are created randomly from the original data set. At least 2000 samples are sufficient for reliable estimates [17]. 5000 samples were generated in the bootstrap analysis carried out within the scope of this research. Confirmatory factor analysis performed to test the construct validity of the scales used in the research and the mediation model analyzes performed to test the hypotheses were made with the AMOS 24 program. In the AMOS program, the multivariate normality assumption was evaluated with multivariate kurtosis (Mardia's coefficient) and critical ratio value. Although it is widely accepted that the critical rate value should be below 10 , it is stated that this value does not usually cause problems until 20 . In this study, the 
Unweighted Least Squares-ULS method was used as the prediction method because it was determined that the data did not meet the multivariate normality assumption in CFA and mediation analysis [18].

Table 1

Confirmatory factor analysis fit indices

\begin{tabular}{|llll|}
\hline Fit Indices & Good Compliance & Acceptable Compliance & Model Value \\
\hline $\mathbf{X} 2 / \mathrm{df}$ & $\leq 3$ & $\leq 5$ & 0,545 \\
\hline $\mathrm{GFI}$ & $0,95 \leq \mathrm{GFI} \leq 1,00$ & $0,90 \leq \mathrm{GFI} \leq 0,95$ & 0,967 \\
\hline AGFI & $0,90 \leq \mathrm{AGFI} \leq 1,00$ & $0,85 \leq \mathrm{AGFI} \leq 0,90$ & 0,964 \\
\hline NFI & $0,95 \leq \mathrm{NFI} \leq 1,00$ & $0,90 \leq \mathrm{NFI} \leq 0,95$ & 0,955 \\
\hline RMR & $0<\mathrm{RMR} \leq 0.05$ & $0,05<\mathrm{RMR} \leq 0,08$ & 0,024 \\
\hline SRMR & $0<\mathrm{SRMR} \leq 0.05$ & $0,05<\mathrm{SRMR} \leq 0,08$ & 0,052 \\
\hline
\end{tabular}

In confirmatory factor analysis, the empathic tendency scale, life satisfaction scale, and professional selfesteem scale were tested in the same model [18]. Scale items were included in the model as observed variables, and covariances were drawn between the implicit variables; empathic characteristics, life satisfaction, and professional self-esteem. According to the fit indices in Table 1, the model is determined to be compatible and valid with the data [18].

The kurtosis and skewness values were used to detect whether the data showed a normal distribution or not. Since the skewness and kurtosis values were in the range of \pm 2 [19], it was found that the data did not show an excessive deviation from the normal distribution. After calculating the total scores of the scales, the correlative relationship between the variables was evaluated with the Pearson Moments Product correlation coefficient in SPSS 23 program. The reliability of the scales was evaluated with the CA internal consistency coefficient and Composite Reliability (CR) coefficient. The CA internal consistency coefficient and CR value are required to be at least $0.7(18,20)$.

\section{Results}

The results of the statistical analyses are included in this section. The correlation and reliability findings of the variables are presented in Table 2: 
Table 2

Correlation, reliability and statistical findings of variables

\begin{tabular}{|llllllll|}
\hline Variables & $\mathbf{1}$ & $\mathbf{2}$ & $\mathbf{3}$ & Mean & Std. Deviation & CA & CR \\
\hline 1. Empathic Tendency & 1 & & & 75,40 & 6,02 & 0,825 & 0,820 \\
\hline $\begin{array}{l}\text { 2.Professional } \\
\text { Self-Esteem }\end{array}$ &, $327^{\star *}$ & 1 & & 124,95 & 12,55 & 0,948 & 0,948 \\
\hline 3.Life Satisfaction &, $332^{* *}$ &, $365^{\star *}$ & 1 & 24,00 & 3,69 & 0,775 & 0,773 \\
${ }^{* *} p<0,01$ & & & & & & & \\
\hline
\end{tabular}

When Table 2 is analyzed, it is observed that there is a positive and significant relationship among empathic tendency, life satisfaction and professional self-esteem scores. In addition, the scales are seen to be reliable according to the CA and CR coefficients. The research models realized to test the research hypotheses are presented below in a certain systematic (Hypothesis 1-4). Empathic tendency, professional self-esteem and life satisfaction variables were included in the SEM analysis as they were in the CFA analysis. Empathic tendency, professional self-esteem and life satisfaction, which are scale items (observed variables), were included in the analysis as implicit variables. SEM analysis findings and fit index values of the three models are given in Table 3.

Table 3

SEM analysis findings

\begin{tabular}{|c|c|c|c|}
\hline & \multicolumn{3}{|c|}{ Standardized Prediction ( $\beta$ ) } \\
\hline & Model 1 & Model 2 & Model 3 \\
\hline Life Satisfaction <-- Empathic Tendency & $0,432 *$ & & $0,323 *$ \\
\hline Professional Self-Esteem <-- Empathic Tendency & & $0,425^{*}$ & $0,377^{*}$ \\
\hline \multirow[t]{7}{*}{ Life Satisfaction <-- Professional Self-Esteem } & & $0,467 *$ & $0,312^{*}$ \\
\hline & $\mathrm{X}^{2} / \mathrm{sd}: 1,011$ & $X^{2} /$ sd: 0,673 & $\mathrm{X}^{2} / \mathrm{sd}: 0,545$ \\
\hline & GFI: 0,961 & GFI: 0,959 & GFI: 0,967 \\
\hline & AGFI: 0,953 & AGFI: 0,956 & AGFI: 0,964 \\
\hline & NFI: 0,917 & NFI: 0,945 & NFI: 0,955 \\
\hline & RMR: 0,031 & RMR: 0,027 & RMR: 0,024 \\
\hline & SRMR: 0,066 & SRMR: 0,055 & SRMR: 0,052 \\
\hline$*_{p}<0,05$ & & & \\
\hline
\end{tabular}

In the light of the information given in Table 3, the first model made in the research is given in Figure 2: 
According to the findings of the first model analyzed, it is determined that empathic tendency positively affects life satisfaction $(\beta=0,432 ; p<0,05)$ and compliance values are given in Table 3 . As seen in Table 3 , the model analyzed was determined to be compatible and valid with the data according to the fit indices. In this case, the Hypothesis 1: "Empathic tendency positively affects life satisfaction" was supported.

The second model for testing research hypotheses is given in Figure 3:

When the 2nd Model data in Figure 3 is examined; it is determined that empathic tendency positively affects professional self-esteem $(\beta=0.425 ; p<0.05)$ and professional self-esteem positively affects life satisfaction $(\beta=0.467 ; p<0.05)$. Model 2 fit index values are given in Table 3 . In this case, the Hypothesis 2: "Empathetic tendency positively affects professional self-esteem" and the Hypothesis 3: "Professional self-esteem affects life satisfaction positively" were supported.

In order to determine the mediation effect after this process, the model of the professional self-esteem was included in the model and the model was re-established and the Model 3 fit index values are presented in Table 3 and the structural equation model is presented in Figure 4:

According to the findings of the third model analyzed, empathic tendency positively affects professional self-esteem $(\beta=0.377 ; p<0.05)$, professional self-esteem positively affects life satisfaction $(\beta=0.312 ; p$ $<0.05)$ and it was found that the positive effect of empathic tendency on life satisfaction $(\beta=0.323 ; p$ $<0.05$ ) decreased. This shows that professional self-esteem has a "partial" mediating effect in the relationship between empathic tendency and life satisfaction. Thus, Hypothesis 4: "Professional selfesteem mediates the relationship between empathic tendency and life satisfaction" was supported.

The mediation effect supported above based on the causality approach of Baron and Kenny [15] was also tested by the modern method. According to the findings of the mediation effect analysis performed with the Bootstrap method, it was determined that the indirect effect of empathic tendency on life satisfaction through professional self-esteem was significant $(\beta=0,118 ; \% 95 \mathrm{GA}[0,085,0,156])$.

According to these results, the Hypothesis 4: "Professional self-esteem mediates the relationship between empathic tendency and life satisfaction" was also supported by modern method since indirect effect values did not include 0 (zero) value in $95 \%$ confidence interval.

\section{Discussion}

This research aims to demonstrate the relationship among empathic tendencies, life satisfaction and professional self-esteem of the students of the Medical Faculty, Nursing and Health Vocational School. In addition, in this study, it was tried to determine whether there is a mediating role of professional selfesteem among the empathic tendency and life satisfaction of the students receiving health education. In our study, it is seen that the level of empathic tendency of the participants is high. When the studies on health workers and students were examined in the literature, empathic tendency levels were found high in the studies conducted with military nursing students in Turkey by Pazar et al. [5], with military medicine and nursing students by Özcan et al. [21], with nurses by Guven Ozdemir and Sendir [22], with nursing 
students in Italy by Ferri et al. [23], and with paramedics, nursing and midwifery students in Australia by Williams et al. [24]. Studies show that students studying in the field of health have higher empathy levels than students in other fields [1]. This situation makes us think that students who prefer the field of health probably have a certain ability and motivation to understand and conduct the relationship in a healthy way, which constitutes an important aspect of health care [23].

When students' life satisfaction levels are examined, it is seen that they are satisfied with their lives. When the studies in the literature were examined, life satisfaction levels were found to be high in the studies conducted with the students of medicine and dentistry in Saudi Arabia by Aboalshamat et al. [25], with medical students in China by Wang et al. [26], with nursing students in Korea by Kim [27]. As individuals with high life satisfaction have a psychologically, socially and physically healthy life, high level of social functionality, more positive relationships in their social environments, a cognitive structure and productivity that are open to personal development, compatible with their lives [28], it is thought that the high level of life satisfaction of individuals in the health sector will have a positive impact on health services.

It is seen that students in our study have high levels of professional self-esteem. When literature review was done in this field, Similarly, professional self-esteem was found to be high in the studies performed with university students in Iran and Turkey by Khezerlo [29], in Pakistan by İqbal et al. [30], with the nursing students in China by Kim [31], with social workers and nursing students by Bekar et al. [32], with nursing students by Sarikoc and Kaplan [33]. Healthcare professionals and students have a great responsibility for their roles in the healthcare industry. It is thought that having a positive feeling towards their profession and respecting their job will result in happy working life and therefore positively affect the provision of health services.

When the relationships between the variables in our study were analyzed, a positive significant relationship and effect were found between empathic tendency and life satisfaction. Research results are compatible with the literature [34,35]. In the study by Guler and Gazioglu [36], the variables predicting life satisfaction in university students were examined, and it was found that empathy was the variable that predicted life satisfaction the most. Yetim [37], emphasizes that when people develop a social relationship in which they develop a deep understanding of each other and complement each other harmoniously, they are happier and their life satisfaction is higher. Considering that the tendency of empathy in individuals is high, it is thought that the satisfaction they receive from life is more and better relationships can be developed [38].

In our study, a positive and significant relationship was found between empathic tendency and professional self-esteem. The results of the study are similar to the literatüre [39-41]. The health sector needs healthcare professionals who can empathize in order to maintain a healthy patient-healthcare relationship, to approach the patient with understanding, to understand and feel their lives and feelings. Therefore, it is evaluated that students who will lead this sector in the future by studying in the field of 
health are people with high empathic tendency and they make their career choices in this direction and respect their profession.

In our study, a positive significant relationship and effect were found between professional self-esteem and life satisfaction. Study findings are similar to previous studies [42-44]. Choosing a profession is one of the important and critical decisions in life. After choosing the profession, the individual receives years of education about his/her profession, spends energy and effort to be successful, and gains knowledge and skills related to the profession's subtleties. The health worker does not only earn a living in the work environment, but also gains happiness from his work, provides psychological satisfaction, acquires a respectable place in the society, and provides satisfaction by applying his effort, knowledge, skill and ability to his work. Therefore, respecting and loving healthcare professionals will increase the satisfaction they will receive from life [45].

Finally, the mediating role of professional self-esteem in the relationship between empathic tendency and life satisfaction was examined in our study, and the statistical data obtained showed that the established model confirmed this hypothesis, that professional self-esteem had an intermediary role between empathic tendency and life satisfaction. In the established model, it was observed that the significant effect of empathic tendency on life satisfaction decreased when the professional self-esteem came into play. This data indicates that professional self-esteem plays a "partial" mediation role and shows that it is an important predictor of life satisfaction. It is concluded that empathic tendency and professional self-esteem are two important factors that affect life satisfaction and that these factors should also be increased in order to increase life satisfaction. In the literature review, no other study examining the relationships between the relevant variables in the same setup (a mechanism) was found.

\section{Conclusion}

The empathic tendency, life satisfaction and professional self-esteem levels in military students receiving health education are high. There is a positive and significant relationship between the variables examined. It was found that professional self-esteem has a partial mediating role in the relationship between empathic tendency and life satisfaction. When healthcare professionals are happy with their lives, it will cause them to be more productive in their private and business lives, establish a more positive relationship with their colleagues and patients, and improve themselves and then this will reflect positively on health services. Empathy should be included in the education curriculum and courses should be organized in order to increase satisfaction with life and interviews and panels should be organized with people who are role models in the field of health through the professional chambers. Studies can be conducted in which different variables are modeled that reveal factors that have a positive or negative effect on the life satisfaction of the individual. It would be useful to conduct scientific studies on practice with especially different research methods and patterns. Studies that will make comparisons among students studying in military-civilian or health-non-health areas could be planned. Longitudinal studies could be designed that allow comparing the situation before and after graduation. 


\section{Abbreviations}

GMMA: Gulhane Military Medical Academy, SPSS: Statistical Package for the Social Sciences, ETS: Empathic Tendency Scales, PSES: Professional Self-Esteem Scale, LSS: Life Satisfaction Scale, SEM: Structural Equation Modeling, CFA: Confirmatory Factor Analysis, CR: Composite Reliability.

\section{Declarations}

\section{Ethics approval and consent to participate}

Ethics committee permission was taken from the Gülhane Military Medical Academy (2015 / 506874691491-36-14/1648.4-74) for the research. Participants signed the informed consent form before the study.

\section{Competing interests}

All authors declare that they have no competing interests.

\section{Authors' contributions}

YU participated in the design and conception of the study and its coordination, acquisition of data, carried out statistical analysis and drafted the manuscript. FO participated in the conception of the study and participated in the design of the study, reviewed analysis and manuscript.

\section{Acknowledgements}

We would like to thank military health students who participated in the research helpfully and devotedly without expecting material compensation.

\section{Availability of data and materials}

The datasets used and/ or analyzed during the current study are available from the corresponding author upon reasonable request

\section{Consent for publication}

Not applicable.

\section{Funding}

No funding was provided for this study.

\section{References}

1. Petrucci C, La Cerra C, Aloisio F, Montanari P, Lancia L. Empathy in health professional students: A comparative cross-sectional study. Nurse Educ Today. 2016;41:1-5. 
2. Hàkansson J, Montgomery H. Empathy as an interpersonal phenomenon. J. Soc. Pers. Relatsh. 2003;20(3): 267.

3. Strayer J, Roberts W. Children's personel distance and their empathy:Incides of International closeness. Int. J. Behav. Dev. 1997;20(3): 385-403.

4. Sahin E, Ersanlı E, Kumcagiz H, Barut Y, Ak E. Sociodemographic differences in empathic tendency:A sample of religious high school students. Journal of Studies in Education. 2014;4(4): 1-11.

5. Pazar B, Demiralp M, Erer I. The communication skills and the empathic tendency levels of nursing students: a cross-sectional study. Contemp Nurse. 2017;53(3): 368-77.

6. Park N, Peterson C, Seligman MEP. Strength of character and well-being. J Soc Clin Psychol. 2004;23(5):607.

7. Arkar H, Sari O, Hidaner H. Relationships between quality of life perceived social support social network and loneliness in a Turkish sample. Yeni Symposium Psikiyatri, Nöroloji ve Davranış Bilimleri Dergisi. 2004;42: 20-7.

8. Aricak T, Dilmac B. Psikolojik danışma ve rehberlik öğrencilerinin bir takım değişkenler açısından benlik saygısı ile mesleki benlik saygısı düzeylerinin incelenmesi. Trakya Üniversitesi Sosyal Bilimler Dergisi. 2003;3(1): 1-7.

9. Aral N,Gursoy F, Ceylan R, Bicakci M.Y. Examination of the professional self-esteem of teacher candidates studying at a faculty of education. Pol Futures Educ Internet. 2009;7(4): 424.

10. Tabassum F, Ali MA. Professional Self-esteem of secondary school teachers. Asian Soc. Sci.2012;8(2): 206.

11. Dokmen U. A new measurement model of the empathy and developing empathy by using psychodrama. Journal of Education Faculty of Ankara University. 1988;21:155-68.

12. Diener E, Emmons RA, Larsen RJ, Griffin S. The satisfaction with life scale. J. Pers. Assess. 1985;49(1): 71-5.

13. Koker S. Comparison of normal and problematic adolescents' life satisfaction level. Master Thesis; Ankara University; Ankara;1991.

14. Arıcak T. Psychological counseling practice with a group aimed at improving teacher candidates' self-esteem and professional self-esteem. Marmara University Journal of Educational Sciences. 1999;11: 11-22.

15. Baron R M, Kenny DA. The moderator-mediator variable distinction in social psychological research: conceptual, strategic, and statistical considerations. J Pers Soc Psychol. 1986;51(6):1173.

16. Fritz M S, MacKinnon DP. Required sample size to detect the mediated effect. Psychol. Sci. 2007;18(3):233-39.

17. DiCiccio TJ, Efron B. Bootstrap confidence intervals. Stat Sci. 1996;11(3):189-212.

18. Gurbuz S. AMOS ile yapısal eşitlik modellemesi. Seçkin Yayınevi; Ankara;2019.

19. Pituch KA, Stevens JP. Applied multivariate statistics for the social sciences. 4th ed.; Routledge;New York; 2012. 
20. Yaşlıoglu MM. Factor analysis and validity in social sciences: Application of exploratory and confirmatory factor analyses. Istanbul Business Research. 2017;46, 74-85.

21. Ozcan CT, Oflaz F, Bakir B. (2012). The effect of a structured empathy course on the students of a medical and a nursing school. Int Nurs Rev. 2012;59(4): 532-38.

22. Guven Ozdemir N, Sendir M. The relationship between nurses' empathic tendencies, empathic skills, and individualized care perceptions. Perspect Psychiatr C. 2020;doi:10.1111/ppc.12489.

23. Ferri P, Rovesti S, Panzera N, Marcheselli L, Bari A, Di Lorenzo R. Empathic attitudes among nursing students: a preliminary study. Acta Biomed.2017; Jul 18;88(3S):22-30.

24. Williams B, Brown T, Boyle M, McKenna L, Palermo C, Etherington J. Levels of empathy in undergraduate emergency health, nursing, and midwifery students: a longitudinal study. Adv Med Educ Pract. 2014;5: 299-306.

25. Aboalshamat KT, Alsiyud AO, Al-Sayed RA, Alreddadi RS, Faqiehi SS, Almehmadi S. A. The relationship between resilience, happiness, and life satisfaction in dental and medical students in Jeddah, Saudi Arabia. Niger J Clin Pract. 2018;21(8):1038-43.

26. Wang Q, Wang L, Shi M, Li X, Liu R, Liu J, et al. Empathy, burnout, life satisfaction,correlations and associated socio-demographic factors among Chinese undergraduate medical students:an exploratory cross-sectional study. BMC Med. Educ. 2019;19:341.

27. Kim J. Nursing students' relationships among resilience, life satisfaction, psychological well-being, and attitude to death. Korean J Med Educ.2019; 31(3): 251-60.

28. Erol M, Kaba I. Investigation of life satisfaction of adolescents'. Journal of Social and Humanities Sciences Research. 2018;5(16):52-63.

29. Khezerlou E. Professional self-esteem as a predictor of teacher burnout across Iranian and Turkish EFL teachers. IJLTR. 2017;5(1):113-30.

30. Igbal HM, Bibi F, Gul A. Adaptation and validation of Aricak's professional self-esteem scale for use in the Pakistani context. The European Journal of Social and Behavioural Sciences.2016;16: 2055-66.

31. Kim JS. Relationships between reality shock, professional selfconcept, and nursing students' perceived trust from nursing educators: A cross-sectional study. Nurse Educ Today. 2020;https://doi.org/10.1016/j.nedt.2020.104369

32. Bekar EO, Sener DK, Yilmaz C, Cangur S. The evaluation of professional self-esteem of nurses and social workers before and after graduation. Journal of Health and Nursing Management. 2017;4(2):50-5.

33. Sarikoc G, Kaplan M. Examining The relationship between the social and emotional learning skills, professional self-esteem and academic major satisfactions of the nursing students. Florence Nightingale Journal of Nursing. 2017;25(3): 201-8.

34. Cevik GB. The role of anger, life satisfaction, and coping with stress in predicting empathic tendencies of school administrators. Education and Science. 2017;42(191):283-305. 
35. Bastug G. The investigation of relation between empathic skill and life satisfaction of volleyball trainer candidates. Nigde University Journal of Physical Education and Sport Sciences.2009;3(3):222-7.

36. Guler CY, Gazioglu AEI. Subjective well being, psychiatric symptoms and some other characteristic properties among the students of guidance and psychological counselling. Buca Faculty of Education Journal. 2008;23:107-14.

37. Yetim U. Toplumdan Bireye mutluluk resimleri. Baglam Publishing; Istanbul;2001.

38. Kaya OS, Orcan F. Mediating role of happiness between empathy, forgiveness, life satisfaction: a path analysis. Bolu Abant Izzet Baysal University Journal of Faculty of Education.2019;19(2):540-54.

39. Sa B, Ojeh N, Majumder AA, Nunes P, Williams S, Rao SR, et al. The relationship between self-esteem, emotional intelligence, and empathy among students from six health professional programs. Teach Learn Med. 2019; doi: 10.1080/10401334.2019.1607741

40. Huang L, Thai J, Zhong Y, Peng H, Koran J, Zhao XD. The positive association between empathy and self-esteem in Chinese medical students: A multi-institutional study. Front. Psychol.2019;10:1921.

41. Perez-Fuentes MC, Jurado MMM, Pino RM, Linares JJG. Emotional intelligence self-efficacy and empathy as predictors of overall self-esteem in nursing by years of experience. Front. Psychol.2019;10: 2035.

42. Oz SD, Yildiz G. Determination of the satisfaction levels of nursing students on their professional self-esteem and education. Journal of Health and Nursing Management. 2019;2(6):79-89.

43. Aktac V, Cetinkaya M. Investigation of science teacher candidates' professional self-esteem and life satisfaction. JCER. 2019;7(14):575-99.

44. Carmel S. The professional self-esteem of physicians scale, structure, properties, and the relationship to work outcomes and life satisfaction. Psychol. Rep.1997; 80: 591-602.

45. Civilidag A, Yanar A, Kizilirmak B, Denizli T. An analysis levels of professional self esteem, trait anxiety and life satisfaction. Life Skills Journal of Psychology.2018;2(3):45-60.

\section{Figures}

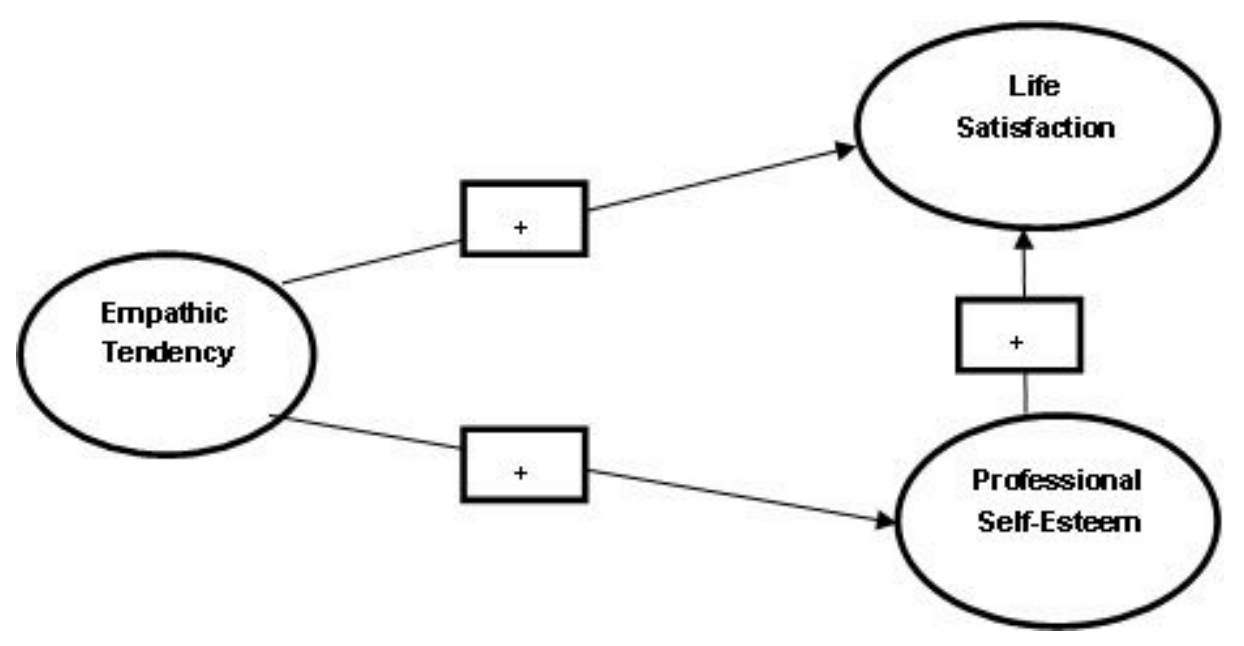

Page $14 / 16$ 
Figure 1

Research model
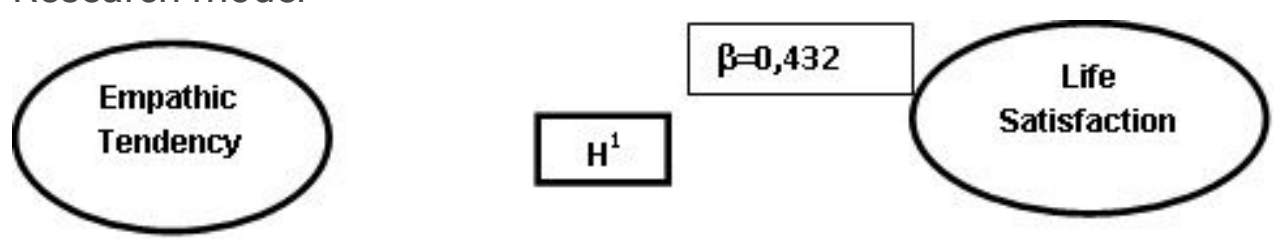

Figure 2

Empathic tendency- Life satisfaction structural equation model

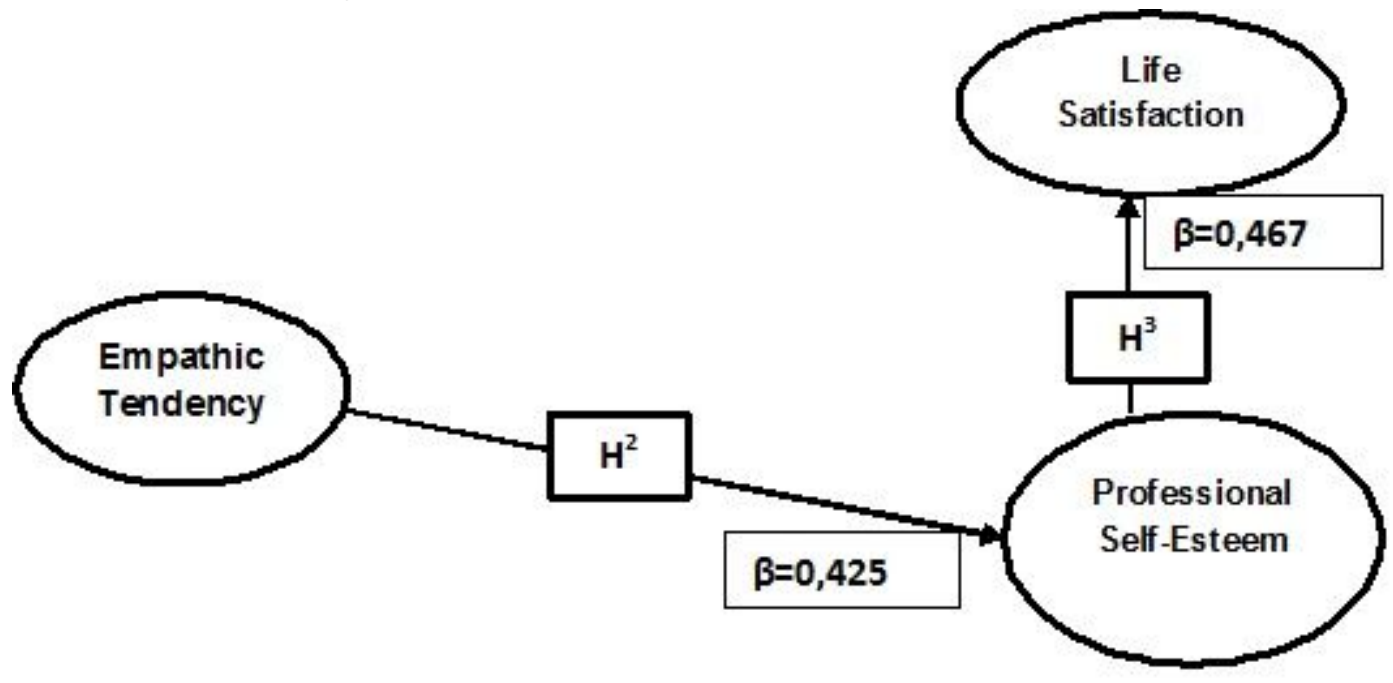

Figure 3

Empathic tendency-professional self-esteem and professional self-esteem -life satisfaction structural equation models

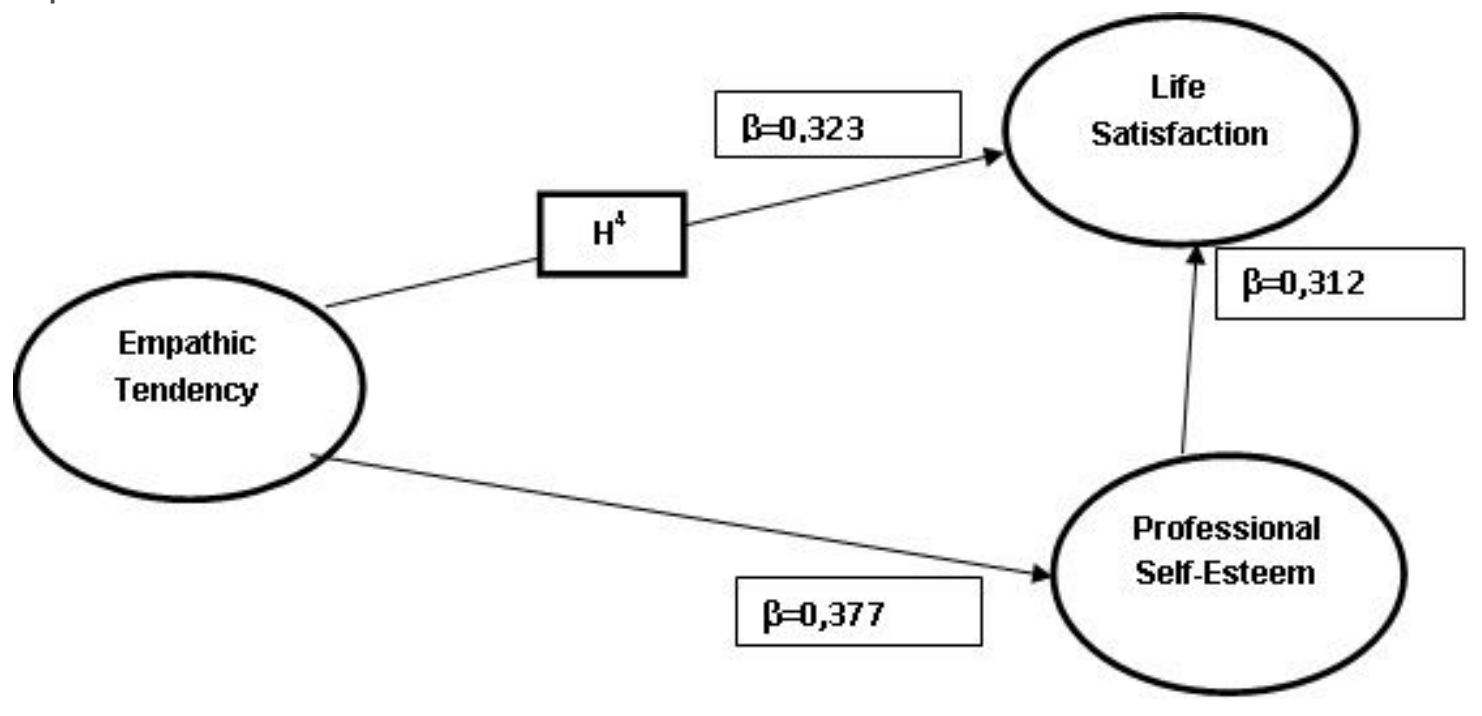

Figure 4 
Empathic tendency - Life satisfaction - Professional self-esteem structural equation mediation model 